intensive, investigations. Alternatively these patients refused to accept a psychiatric explanation and turned to alternative medicine, as did one of our patients. Our patient consulted a homoeopath, who again gave reassurance.

\section{NEED TO CHANGE ATTITUDES}

The cognitive and behavioural approach gives us a new model, and we have shown that it can be applied in a general hospital. Nevertheless, it took one year to recruit the six patients from consultants. The medical profession is conservative in its approach to new treatments, and perhaps a sense of failure at their own approach militated against referral. Going further one could propose the condition has a large iatrogenic component, being caused by doctors' belief in physical causes of illness and compliance with patients' demands for further tests despite previous fruitless investigations. ${ }^{10}$

Bass and Murphy point out that in the white paper Working for Patients ill health was reduced to a consumer need for ever expanding diagnostic procedures, and talking with patients to help them see their symptoms another way would be unprofitable. ${ }^{10}$ Most psychiatrists have little experience of working in a general hospital, just as most physicians have no training in the psychological approaches described in this study. The role of the psychiatrist in the general hospital has been discussed by Crisp, who proposed: "Ultimately his position will be dictated, apart from his own inclination and interest, by whether he is seen to be and found to be of value by his medical colleagues."

This is a small study of only six patients. The results of a cognitive and behavioural approach in hypochondriasis are encouraging, but further studies in more patients are needed before this approach is generally advocated.

1 Barsky AJ, Geringer E, Wood CA. A cognitive-educational treatment for hypochondriasis. Gen Hosp Psychiatry 1988;10:322-7.

Barsky AJ, Wyshak G. Hypochondriasis and somatosensory amplification. Br f Psychiatry 1990;157:404-9.

3 Goldberg D, Bridges K. Somatic presen care settings. F Psychosom Res 1988;32:137-44.

Salkouskis PM, Warwick HMC Morbid preoccupations, hellh anxisty and resu, Warwick Hive. Morbid preocupatons, health anxiety Behav Res Ther 1986.24:597-602. American Psychiatric Association. disorders. 3rd ed. Washington, DC: APA, 1987.

igmund AS, Snaith RP. The hospital anxiety and depression scale. Acta Psychiatr Scand 1983;67:361-70.

7 Beck AT, Rush JA, Shaw BF, Emery G. Cognitive therapy of depression New York: Guilford Press, 1979.

8 Ellis A. Reason and emotion in psychotherapy. New York: Lyle Stuart, 1962.

9 Barsky AJ, Klerman GL. Overview: hypochondriasis, bodily complaints, and somatic styles. Am f Psychiatry 1983;140:273-83.

10 Bass $C$, Murphy $M$. The chronic somatiser and the government white paper. fR Soc Med 1990;83:203-5.

11 Crisp AH. The role of the psychiatrist in the general hospital. Postgrad Med f 1968;44:267-76.

(Accepted 30 August 1991)

\title{
Detention of British citizens as hostages in the Gulf-health, psychological, and family consequences
}

\author{
J A Easton, S W Turner
}

\begin{abstract}
Objective-To describe the physical, psychological, and family consequences of the detention of British subjects as hostages in Kuwait or Iraq, or both, after the invasion of Kuwait on 2 August 1990 and to investigate the relation between types of trauma experienced and these reactions.

Design-Postal questionnaire.

Subjects -381 respondents.

Results - Many health, social, and psychological sequelae were identified. Problems with present finance, accommodation, and work are important causes of distress. Many hostages coped well and gained self esteem.
\end{abstract}

Conclusions-A minority of respondents require further support and treatment. Expatriates in risk areas should retain assets in their home country.

\section{Introduction}

Over 1200 British citizens, the largest Western national group, were held against their will in Kuwait and Iraq following the invasion of Kuwait on 2 August 1990. Not all were people who lived or were staying in the area; a British Airways jet in transit through Kuwait was detained with all passengers. Most went into hiding or were taken by Iraqi guards to strategic sites, where they were described as a "human shield." Many of the women and children were released in September; other hostages escaped or obtained freedom following humanitarian initiatives but most were held until their unexpected release in mid-December 1990.

One of us (JAE) had visited Baghdad as medical adviser on one of the missions in October 1990. This experience and the sudden release of all the remaining detainees led to the present investigation of former hostages and their families.

Ideally, an unbiased sample of all the hostages would have been selected for study.' In this case the suddenness of the release of more than 1000 people, many of whom had lost their homes; their immediate dispersal throughout the United Kingdom and beyond; and the non-existence of an accurate database rendered such sampling impossible. Nevertheless many possible contact addresses were obtained from sources such as the Gulf support groups and personal recommendations.

The retention of hostages in this conflict was unusual for several reasons: large numbers of people, most of whom had perceived no prior risk, were detained 윽 without warning; as well as losing their freedom, many N were taken to strategic sites apparently as human deterrents against military attack; there was usually no opportunity for a personal relationship between hostage and responsible captor, which is probably essential for the development of the Stockholm syndrome ${ }^{2}$ (in which some hostages develop a positive or even protective feeling towards their captors); it is very unusual for so many Western citizens to be subjected to the state repression widely reported to occur in Iraq. ${ }^{3}$

Previous studies have examined the psychological conditions of individuals held hostage ${ }^{2}$ civilians subjected to normal war trauma, ${ }^{4}$ and refugees subjected to state organised violence within their own countries. There is now widespread interest in post-traumatic stress disorder ${ }^{67}$ and there is no doubt that a syndrome 8 of this type follows a wide range of traumatic events. Post-traumatic stress disorder is known to be associated with increased rates of depression ${ }^{10}$ and alcohol $\rightleftharpoons$ misuse, " yet these alone do not account for the severe functional impairment that may accompany it. After the initial event persistent distress may be related to the 
avoidance behaviour of others and changes in financial status. There may also be important changes in attitudes about personal priorities and values.

\section{Method}

Between 14 April and 31 May questionnaires were sent by post to a total of 828 possible addresses, all those of which we had knowledge. The largest sources of addresses were the card indexes of the Gulf Support Group, which listed relatives and interested people who had sought help or information up to eight months earlier.

The questionnaire invited recipients to provide basic personal information and to answer questions on the events in the Gulf, their treatment there and on return, as well as their current condition and that of their families. The 28 item form of the general health questionnaire ${ }^{1213}$ and the impact of event scale ${ }^{14}$ were also included. (An alternative version of the general health questionnaire, for example using the word "stress" rather than the word "strain" in question B3, was selected as this seemed to be more easily comprehensible to people in the sample, some of whom had been long exposed to other cultures..$^{15}$ )

The traumatic events were categorised under three headings: threat events; loss events (relating to the Gulf); and loss events (domestic and continuing). Allocation to categories was carried out in advance of the inferential analyses. These items are listed in table I. Attitude change was assessed with a series of five questions about priorities, estrangement, and values (summarised in table II), which were extracted from the semistructured torture assessment record (S W Turner, unpublished data). A copy of the questionnaire is available from us.

Statistical analyses were carried out using the statistical package for the social sciences. ${ }^{16}$ Percentages are presented as valid percentage scores, omitting missing values from each calculation.

The study was carried out with the approval of the Foreign and Commonwealth Office Emergency Unit, the Gulf Support Group London, the Gulf Support Group Coventry, and Hostages of the Middle East.

\section{Results}

DESCRIPTION OF THE SAMPLE

At the time of this analysis, 401 replies had been received ( $48 \%$ return rate). Twenty replies simply confirmed that an address was incorrect, leaving 381 valid returns. The mean age of the sample was $42 \cdot 0$ (SD $10 \cdot 3)$ years; $316(83 \%)$ respondents were men. Respondents were healthy, only five (1\%) having physical health problems and $14(4 \%)$ a history of emotional or psychological difficulties. Three hundred

TABLE I - Number (percentage) of respondents experiencing traumatic events

\begin{tabular}{lrr}
\hline & Yes & No \\
\hline Threatening events: & & \\
$\quad$ Thought they might be killed $(\mathrm{n}=368)$ & $299(81)$ & $69(19)$ \\
Thought someone close might be killed $(\mathrm{n}=377)$ & $222(59)$ & $155(41)$ \\
Witnessed fighting $(\mathrm{n}=358)$ & $217(61)$ & $141(39)$ \\
Witnessed threat to civilians $(\mathrm{n}=376)$ & $125(33)$ & $251(67)$ \\
Experienced personal threats $(\mathrm{n}=378)$ & $113(30)$ & $265(70)$ \\
Witnessed violence to civilians $(\mathrm{n}=378)$ & $80(21)$ & $298(79)$ \\
Witnessed someone being killed $(\mathrm{n}=376)$ & $41(11)$ & $335(89)$ \\
Experienced personal violence $(\mathrm{n}=377)$ & $30(8)$ & $347(92)$ \\
Loss events $($ Gulf $)$ & & \\
Loss of personal or sentimental items $(\mathrm{n}=378)$ & $337(89)$ & $41(11)$ \\
Separated from friends during episode $(\mathrm{n}=375)$ & $283(76)$ & $92(25)$ \\
Left friends behind on release $(\mathrm{n}=371)$ & $240(65)$ & $131(35)$ \\
Separated from relatives during episode $(\mathrm{n}=372)$ & $196(53)$ & $176(47)$ \\
Left relatives behind on release $(\mathrm{n}=377)$ & $47(13)$ & $330(87)$ \\
Loss events $($ domestic and continuing $)$ & & \\
Serious loss of property $(\mathrm{n}=377)$ & $274(73)$ & $103(27)$ \\
Loss of job or livelihood $(\mathrm{n}=367)$ & $202(55)$ & $165(45)$ \\
Serious financial problems $(\mathrm{n}=379)$ & $169(45)$ & $210(55)$ \\
Serious accommodation problems $(\mathrm{n}=380)$ & $53(14)$ & $327(86)$ \\
\hline
\end{tabular}

TABLE II-Number (percentage) of respondents whose attitudes had changed as a result of detention

\begin{tabular}{lrc}
\hline & Yes & \multicolumn{1}{c}{ No } \\
\hline Lasting change in priorities $(n=373)$ & $272(73)$ & $101(27)$ \\
Feel different from other people $(\mathrm{n}=375)$ & $245(65)$ & $130(35)$ \\
Frequently feel misunderstood by others $(\mathrm{n}=379)$ & $194(51)$ & $185(49)$ \\
Changed political views $(\mathrm{n}=377)$ & $135(36)$ & $242(64)$ \\
Changed religious beliefs $(\mathrm{n}=379)$ & $78(21)$ & $301(79)$
\end{tabular}

and twenty eight $(86 \%)$ had lived in the Middle East and $279(74 \%)$ reported they had close knowledge of Arab customs. Only $68(18 \%)$ had believed that they were taking risks by being in the Middle East. Thirty two $(8 \%)$ respondents were from the BA 149 flight held in Kuwait, 280 (74\%) were from Kuwait, and $36(10 \%)$ from Iraq. Many people were moved during this period; a total of $195(51 \%)$ were detained on strategic sites (mean duration 11.8 (5.4) weeks).

\section{TRAUMATIC EVENTS}

For people who went into hiding in Kuwait conditions were sometimes reasonable, especially in suburbs away from troop areas. Others had homes destroyed in fighting or were afraid of raids by looting soldiers and, short of food and water, hid in attics up to 14 hours a day under hot tin roofs. A smaller number were assaulted; several men were forced to watch their wives being raped. News from the BBC World Service, Gulf Link, and Cable News Network was highly valued. Three quarters received direct help from the Kuwaiti resistance, which functioned almost at once, with deliveries of food, water, medicines, and news; moves to safer districts; disguises and false papers; and sometimes successful escapes.

Among expatriates in Kuwait subsequent financial losses were most severe because of loss of employment, homes, and businesses, often "everything we had."

In all, $202(55 \%)$ had lost their livelihood as a result of the invasion, and of these 123 remained unemployed.

Large numbers of hostages were moved by armed guards to military, chemical, and communications strategic sites, where they were told they would be the first to die in any military attack. Many subjects reported that even their guards were afraid; they described a primitive and unhealthy environment with poor sanitation, "warmed scraps of food left over by the minders," and "yellow rice slops contaminated with rodent faeces." Others reported that they were cared for decently in the circumstances, that their guards felt guilty, and that overcrowding lessened after other nationalities were released.

Three hundred and thirteen (83\%) respondents reported weight loss, often considerable, many losing $18-25 \mathrm{~kg}$. They often had to contend with news or rumours such as the death of a friend, that the allies would wait two years for sanctions to work, that the hostages were expendable, and that chemical weapons might be used. Two hundred and ninety nine $(81 \%)$ thought they might be killed.

Table I summarises eight threats perceived by hostages in the Gulf. Scoring one for each threat, the mean score for the 332 respondents out of a possible eight was $3 \cdot 1$ (SD 1.8). Five events are categorised as losses incurred in the Gulf; scoring one for each, the mean score was $3.0(\mathrm{SD} 1 \cdot 2)$. Four loss events categorised as domestic and continuing were similarly scored, producing a mean score of $1.9($ SD 1.2) from a maximum of four.

\section{HEALTH CONSEQUENCES}

One hundred and seventy three $(47 \%)$ respondents reported that their physical health deteriorated in the Gulf. Some reported serious problems, including untreated bacillary and amoebic dysentery, giardiasis, 
and lack of drugs. One pregnant woman lost $10 \mathrm{~kg}$ and had repeated untreated blood loss.

\section{PSYCHOLOGICAL REACTIONS}

Individuals reported a range of psychological problems while detained, including impaired concentration, indecisiveness, and bizarre behaviour in previously stable colleagues. In the investigation of the current psychological state there was a spectrum of results, with many subjects showing low scores on al the measures and others reporting persistent emotional reactions. A total of 204 (54\%) acknowledged that they sometimes felt guilty to be safely home, but only 39 $(10 \%)$ blamed themselves for their involvement. Scores on the 28 question general health questionnaire and impact of event scale were moderately high (mean $8 \cdot 0$ (SD 7.6) and $24 \cdot 5(17 \cdot 6)$, respectively); with the original cutoff point for the general health questionnaire (scores $>4$ ), $55 \%$ of respondents fell into the "abnormal" category. ${ }^{12}$ Even with a more conservative threshold (scores >12), 100 (27\%) were abnormal on this measure. Similarly, on the impact of event scale $174(49 \%)$ scored in excess of two standard deviations above the mean for medical students following first exposure to the dissecting room (thresholds of 20.5 for men and 34.3 for women) and $74(21 \%)$ scored in excess of the mean stress clinic patient score (threshold $39 \cdot 5) .^{13}$

In the investigation of five possible changes in attitudes (table II), scoring one for each change reported, the mean (SD) score was $2 \cdot 5(1 \cdot 5)$. There was no evidence of the Stockholm syndrome: $315(86 \%)$ reported that even during their detention (and therefore at some considerable personal risk) they wanted the allies to attack.

The association between the nature of the traumatic event and scores on the general health questionnaire and the impact of event scale and of attitude change, was investigated in a multiple regression analysis using data obtained from the subset of $263(69 \%)$ who had provided complete answers to all 65 questions. (Most of the subjects who did not meet this criterion had answered all but one or two questions, which had been left blank.) The maximum intercorrelation between the three independent variables (the two loss scores and the threat score) was 0.39 (between the two loss scores).

For the general health questionnaire, loss (domestic and continuing) was the only significant association with the nature of the traumatic event with a regression coefficient of 2.61 (95\% confidence interval 1.84 to 3.38 ); threat showed a small and non-significant trend with a regression coefficient of $0.51(0.02$ to 1.03$)$. For impact of event scale scores, both loss (domestic and continuing), with a regression coefficient of $3.99(2.25$ to $5 \cdot 73)$, and threat, with a regression coefficient of $2.64(1.45$ to 3.83$)$ were important. Finally, for the attitude change index, experience of threat was the most important $(0.23(0 \cdot 13$ to 0.33$))$, with loss events in the Gulf next $(0.22(0.07$ to 0.37$))$ and losses (domestic and continuing) least important $(0 \cdot 18(0.04$ to $0 \cdot 32$ )).

\section{FAMILY REACTIONS}

One hundred and forty six (47\%) of the 310 married subjects reported an effect on their marriage. Seventy (23\%) described a positive reaction with strengthening of the bond through adversity or other beneficial enhancement. One wrote, "Now we know we can trust each other. We are as close as it is possible to be." Sixty eight $(22 \%)$ reported adverse effects, which they felt resulted from either stress on themselves or behaviour changes in their spouse. Effects include separation, poor communication, and loss of libido. Comments such as "Our lives are ruined" or "My wife will never recover" were common.
Of the 166 respondents with children, $99(66 \%)$ reported the children were affected; in $81(49 \%)$ there were problems such as nightmares, fear of uniforms, nocturnal enuresis, "attention seeking behaviour," and impaired educational performance. Many children were reported to be frightened of letting their parents go abroad again. These effects were said to be present even in children who were in the United Kingdom throughout the episode.

Former hostages were asked if anything good had come out of their experience. Two hundred and fifty one $(68 \%)$ answered positively. The box shows some of the benefits reported. These seem to centre on personal growth and understanding (personal values, self esteem, patience, understanding) and an increased importance attached to relationships (family bonding, other cultures, freedom, religion, friendships)

\section{Some good things reported to have come out of the experience of being hostages}

- Enhancement of personal values

- Increased family bonding

- Improved understanding of other cultures

- Enhanced self esteem

- Cherishing freedom

- Strengthened religious faith

- Friendship forged by shared adversity

- Better understanding of self

- Patience

- "Of comfort, the outcome in general does not encourage hostage taking'”

Subjects were also asked to describe why they thought they had been released. Almost everyone had a different view, and many found this uncertainty hard to resolve. Some examples are listed in the box. Many hostages described anger that Saddam Hussein is still in power, to the extent that "I won't feel free until he's gone."

\section{Some reasons suggested to have determined} release of hostages

- Whim of the Iraqi leader

- Propaganda to influence Western public opinion

- Propaganda to influence Western governments

- Result of a humanitarian mission

- Realisation that the hostage policy was not working

- Embarrassment of captors

- Arab hospitality rules

- Prayer

- Iraq was then prepared for war

- Internal pressures in Iraq's government

- Pressure from leaders of the West

- Pressure from the Soviet Union

- Pressure from Arab allies

- "God knows! This is one of the most difficult, strange things to cope with"

\section{Discussion}

These results represent a large-scale investigation of a discrete group of Western hostages detained in unusual circumstances during an armed conflict, and as such they are of interest. Nevertheless, the limitations of the study must be acknowledged. It was a postal questionnaire design. The fate of non-returns is pure speculation, but we have no doubt that many will never have reached a hostage. In the circumstances the return rate is reasonably high, but there will inevitably have been bias in the response. Two main groups of people are likely to have been lost: firstly, the considerable numbers whose addresses were incorrect, who had been forced to move away from a temporary address, or 
who had chosen to leave Britain; and, secondly, those with frank post-traumatic stress disorder who sough to avoid recollection of the event and who consequently refused to look at material of this type.

Detention had measurable effects on physical and emotional health. Nearly half the sample reported a deterioration in physical health despite a record of previously excellent health. Most lost weight, and in some cases this was extreme. Low morale may have reduced resistance to stress. ${ }^{17}$ The general health questionnaire and the impact of event scale indicated that there had been serious psychological disturbance in about a quarter of respondents. Included with returns were letters and comments from relatives giving anecdotal support to subjects' descriptions of effects on their families. Many relatives felt that they too should be part of a study, and the situation for them in the United Kingdom often seemed to be worse than for the hostages. Merely not knowing what was happening seems to have been a common (and for many, serious) problem. Normal life was completely disrupted, and some say they became ill or aged with worry. From answers to specific questions, there seem to have been important effects on marital and family relationships.

Of more theoretical interest is the relation between the type of trauma and the psychological reaction. Three dependent measures were considered: impact of event scale scores; general health questionnaire scores; and an index of attitude change and alienation. By categorising traumatic events into three classes: threat, loss (Gulf), and loss (domestic and continuing) it is possible to identify differential associations of trauma type with subsequent reaction. Persisting aspects of the trauma and its secondary effect on financial circumstances, accommodation, and work are related to both measures of current symptoms (the general health questionnaire and the impact of event scale). Indeed, this is the only significant association with general health questionnaire scores. For the impact of event scale, a test that is designed to measure recall and avoidance of past traumatic events, the threatening event score is another important association. Only in relation to attitude change does the threat score stand out as the dominant variable, with losses in the Gulf also ahead of domestic and continuing losses. This suggests that the horror of the event and its impact on personal relationships at the time might be important factors in determining subsequent attitude change. This finding has the additional value of suggesting that it is not simply that one variable is more powerful in general; rather, there may be a differential effect of specific independent variables on reaction type.

The losses of property, work, financial independence, and accommodation were important problems for many of the hostages. Some of these losses were inevitable sequelae of the conflict, but it is likely that the effects of these losses on psychological as well as social wellbeing could have been reduced by appropriate support on return to Britain. The anger reported by some subjects towards employers (and others) who seemed to abandon them once they were of no more use contrasts with the more measured and calm responses of those who continued to receive support for themselves and their families throughout this episode.

In conclusion, the extraordinary experiences of British citizens detained in the Gulf seem to be associated with a wide variety of personal and family reactions. Some subjects, although they would not wish to repeat the experience, coped well and received morale boosting support and have gained in self esteem. Others, who feel severely bruised, wish to forget their experiences. For an important minority, perhaps a quarter of subjects, further help is needed.
Few are receiving appropriate or effective aid at present; indeed, many respondents, in their margin notes on the questionnaire, reported feelings of neglect and rejection. One wrote, "Why are we still the forgotten people?" They feel changed by persistent effects on their minds and health and sense injustice that the perpetrators of their suffering are untried and remain in power. Self help through the Gulf support groups and others is likely to be of benefit, particularly in offering support and a common understanding, but is not sufficient for those who are seriously disturbed.

We have four recommendations. Firstly, psychological help should be offered to those still in need. It is now too late for the preventative effects of early critical incident debriefing ${ }^{18}$ to be useful, but similar treatment approaches in which survivors describe their experiences may have beneficial effects on emotional processing ${ }^{1920}$ and lead to reduction of symptoms. Education about the psychological reactions to trauma, individual and family assessments, and specific interventions to deal with identified individual, marital, and family reactions may all be required.

Secondly, these results indicate that resolution of social and financial problems may be prerequisites for psychological recovery. Therefore, solving the issue of financial compensation for losses in Kuwait and Iraq is an urgent priority.

Thirdly, coordinated planning in advance is needed to deal optimally with these psychological and social problems, ${ }^{21}$ to help prevent or at least rapidly identify problems and offer appropriate help in future incidents.

Finally, we recommend that all British expatriates working in high risk areas of the world retain some assets, particularly a home, in the United Kingdom or have insurance against major losses.

We thank the former hostages who took part in this study and Mr Edward Heath, Mr Stewart Eldon, Miss Joanna Copley, Mr Stephen Brookes, Mr Andy Charles, Mr Robert Vaudry, and Bechtel Ltd for their help.

1 Evans SJW. Good surveys guide. BMF 1991;302:302-3.

2 Danto BL. Stress experienced by robbery victims, hostages, kidnapping victims, and prisoners of war. In: Noshpitz JD, Coddington RD, eds. Stressors and the adjustment disorders. New York: Wiley, 1990:294-314.

3 Amnesty International. Amnesty Intermational 1990 report. London: Amnesty International Publications, 1990:125-8.

+ Shaw JA. Stress engendered by military action on military and civilian populations. In: Noshpitz JD, Coddington RD, eds. Stressors and the adjustment disorders. New York: Wiley, 1990:340-61.

5 Turner SW, Gorst-Unsworth C. Psychological sequelae of torture-a descriptive model. Br f Psychiatry 1990;157:475-80.

6 American Psvchiatric Association. Diagnostic and statistical manual. Third edition. Washington, DC: APA, 1980

American Psychiatric Association. Diagnostic and statistical manual. Third edition, revised. Washington, DC: APA, 1987. 8 Wilson J, Raphael B, eds. International handbook of traumatic stress syndromes.

9 Mollica RF, Wyshak G, Lavelle J. The psychosocial impact of war trauma and torture on southeast Asian refugees. Am f Psychiatry 1987;144:1567-72.

10 Kroll J, Habenicht $M$, MacKenzie T, Yang M, Chan S, Vang T, et al. Depression and post-traumatic stress disorder in southeast Asian refugees. Am F Psychiatry 1989;146:1592-7.

11 Davidson J, Swartz M, Storck M, Krishnan RR, Hammett E. A diagnostic and family study of postraumatic stress disorder. Am F Psychiatry 1985;142 90-3.

12 Goldberg DP, Hillier VF. A scaled version of the general health questionnaire. Psychol Med 1979;9:139-45.

13 Goldberg DP. The detection of psychiatric illness by questionnaire. London Oxford University Press, 1972 .

14 Horowitz MJ, Wilner N, Albarez W. The impact of event scale: a measure for subjective stress. Psychosom Med 1979;41:209-18.

15 Raphael B, Lundin T, Weisaeth L. A research method for the study of psychological and psychiatric aspects of disaster. Acta Psychiatrica Scandinavica. 1989;80:1-75.

16 Norusus MJ. Statistical package for the social sciences - personal computer plus V 2.0 base manual. Chicago: Statistical Package for the Social Sciences, 1988.

17 Labuc S. Cultural and societal factors in military organisations. In: Gal R, Mangelsdorff D, eds. Handbook of military psychology. Chichester: Wiley, Mangelsdor $1991: 471-89$.

18 Dyregrov A. Caring for helpers in disaster situations: psychological debriefing. Disaster Management 1989;2:25-30.

19 Horowitz M. Stress response syndromes. New York: Jason Aronson, 1976.

20 Rachman S. Emotional processing. Behav Res Ther 1980;18:51-60.

21 Turner SW, Thompson JA, Rosser RM. The King's Cross fire: planning a "phase two" psychosocial response. Disaster Management 1989;2:31-7.

(Accepted 16 October 1991 